\title{
Pengembangan Bahan Ajar Mata Kuliah Bahasa Indonesia S-2 Semester Satu Pendidikan Dasar Fkip Universitas Bengkulu T.A. 2020/2021
}

\section{Daimun Hambali}

Program Magister Pendidikan Dasar Universitas Bengkulu Daimunhambali@gmail.com

\begin{abstract}
The purpose of this research is to (a) develop teaching materials for Indonesian language courses for Master of Elementary Education (Dikdas) students, (b) to create Indonesian language lecture materials that support students' abilities as candidates for Masters in Basic Education, (c) availability of references Indonesian language material that can be used by students in lectures and the completion of their final project (thesis), and (d) the availability of various references to Indonesian subjects. In addition, the teaching materials for this Indonesian Language Course can be used for research activities; (a) increasing the literacy competence of teaching staff in the Primary Education Study Program, (b) increasing the quality of Indonesian language course material content, and (c) increasing libraries in the S-2 Dikdas Study Program, in improving the quality of lectures and student learning outcomes. This study was designed using a Research and Development approach. Research data collection techniques; interviews and documentation. Data analysis using qualitative analysis. The research output is expected to be; (a) a draft of Indonesian Language Course teaching materials for Master of Basic Education students, and (b) the results of the research will be published in the $S-2$ Basic Education journal, (c) a printed reference book, and (d) obtain an IPR.
\end{abstract}

Keywords: Development, teaching materials, Indonesian language

\section{Pendahuluan}

Pengembangan bahan ajar adalah suatu usaha untuk mengikuti pesatnya perkembangan ilmu pengetahuan, teknologi, dan seni (Ipteks). Perkembangan zaman tanpa diikuti pembaharuan, maka wawasan pengetahuan akan segera tertinggal. Lulusan atau luaran yang dihasilkan tidak mampu berkompetisi untuk menjawab tantangan zaman, terutama ketika memasuki dunia kerja. Dampak lain dari ketertinggalan Iptek akan memengaruhi kualitas mahasiswa dan kualitas 
institusi secara keseluruhan. Pengembangan materi bahan ajar perkuliahan seperti dilakukan dalam penelitian ini, merupakan salah satu bentuk inovasi dalam bidang pendidikan untuk mendukung pelaksanaan pendidikan dan pembelajaran.

Pengembangan materi pembelajaran sangat penting dilakukan dalam meningkatkan aktivitas dan kualitas pendidikan. Tanpa melakukan pengembangan materi bahan ajar, besar kemungkinan akan memengaruhi hasil/luaran dari instutusi tempat mahasiswa menimba ilmu pengetahuan. Bahasa Indonesia merupakan salah satu mata kuliah wajib, termasuk di Prodi S-2 Pendidikan Dasar. Artinya, materi perkuliahan sangat penting dalam meningkatkan kualitas lulusan.

Materi pembelajaran atau perkuliahan wajib selalu diperbaharui dan dikembangkan, karena kebutuhan akan keterbaharuan pengetahuan merupakan hal yang penting. Apa lagi dengan pesatnya Iptek saat ini, hampir semua peserta didik, mulai seusia siswa sekolah dasar sampai ke perguruan tinggi bisa mengakses berbagai informasi melalui jaringan internet. Apabila materi pembelajaran tidak dilakukan pembaruan dan adanya pengembangan, akan berdampak pada kualitas lulusan pada semua lininya.

Prodi S-2 Magister Dikdas merupakan prodi yang mencetak ilmuan dalam bidang ke-SD-an dan praktisi di bidang pendidikan khususnya. Karena itu, muatan mata kuliah di di dalamnya mewadahi bidang kajian lima mata pelajaran yang diajarkan di Sekolah Dasar, yaitu Bahasa Indonesia, Matematika, IPS, IPA, dan PKn. Lima mata pelajaran tersebut merupakan bidang kajian wajib bagi mahasiswa Prodi S-2 Magister pendidikan dasar. Oleh sebab itu, seharusnya dikembangkan sedemikian rupa, agar menarik dan menantang mahasiswa untuk mempelajarinya.

Mata kuliah Bahasa Indonesia adalah sangat dibutuhkan bagi mahasiswa. Kebutuhan itu, bukan hanya sebatas untuk memperoleh nilai yang baik dan dapat membantu untuk menyelesaikan tugas akhir berupa tesis. Akan tetapi, kemampuan berbahasa Indonesia yang dimiliki mahasiswa, baik ketika masih menjadi mahasiswa maupun ketika sudah lulus, sangatlah dibutuhkan pada semua lini kehidupan.

Dalam K-13, kajian materi Bahasa Indonesia terintegrasi dengan bidang studi lainnya. Muatan pembelajaran yang diinginkan dalam K13, sesuai dengan PP No, 19 tahun 2005 peserta didik lebih mengutamakan memiliki kompetensi inti, yaitu kompetensi pedagogik, profesional, kepribadian, dan sosial. Untuk mendukung kualitas mahasiswa sebagai guru atau pun calon guru wajib dibekali materi Bahasa Indonesia. Karena kompetensi bahasa Indonesia baik bersifat reseptif maupun produktif sangat diperlukan sebagai wadah untuk mencari ilmu bidang lainnya. Di samping itu, kompetensi Bahasa Indonesia dibutuhkan untuk berkomunikasi secara umum dan khusus secara lisan dan tulis.

Bahasa Indonesia sebagai mata kuliah wajib bagi mahasiswa prodi S-2 magister Dikdas sangat bermanfaat dan penting pada saat menulis dan mengidit tugas akhir, termasuk tesis. Meteri perkuliahan bahasa Indonesai secara umum telah diterima oleh mahasiswa ketiga kuliah di strata satu. Agar tidak terjadi banyaknya materi tumpang tindah, maka peneliti meminta tanggapan dari mahasiswa, mana-mana materi bahasa Indonesia yang masih sangat mereka butuhkan

Andai muatan materi bahasa Indonesia di S-1 masih sama atau ada kemiripan dengan materi di S-2, besar kemungkinan menyebabkan mahasiswa akan bosan dalam perkuliahan. Karena itu, peneliti berusaha memuat materi yang lebih enovatif terkait dengan kebahasaan, keterampilan berbahasa, bahkan materi kesasteraan.

Dari fenomena tersebut di atas, maka peeliti merasa termotivasi untuk melakukan pengembangan materi bahan ajar perkuliahan Bahasa Indonesia yang telah ada. Hal ini dikarnakan tim pengusul sebagai dosen pengampu mata kuliah Bahasa 
Indonesia, juga merasakan perlunya menginovasi dalam materi kuliah. Keinginan ini juga diperkuat oleh hasil diskusi dengan mahasiswa yang sedang membuat tugas ahkir di prodi S-2 Dikdas.. Mereka sangat membutuhkan keterbaharuan konten kuliah Bahasa Indonesia dalam keterampilan menulis tugas akhir dengan secara rinci.

Tim pengusul telah merencanakan draf bahan ajar perkuliahan Bahasa Indonesia yang selama ini digunakan dalam perkuliahan Bahasa Indonesia. Namun draf bahan ajar itu belum melalui proses penelitian formal. Oleh karena itu, kami berusaha meneruskan kerja melalui penelitian ini.

\section{Metode}

Penelitian ini dirancang dengan menggunakan pendekatan penelitian pengembangan (Resarch and Development), dengan langkah kerja penelitian dimulai dari; (a) validasi pakar, (b) revisi berdasarkan hasil validasi pakar, (c) uji coba terbatas, (d) revisi berdasarkan uji coba, dan (e) uji coba secara luas, (f) revisi berdasarkan uji secara luas, (g) mencetak bahan ajar dalam bentuk buku. Langkah-langkah yang ditempuh dalam penelitian ini adalah dimodifikasi dari langkah-langkah yang dikemukakan Borg and Gall (2003) yang digambarkan di bawah ini.

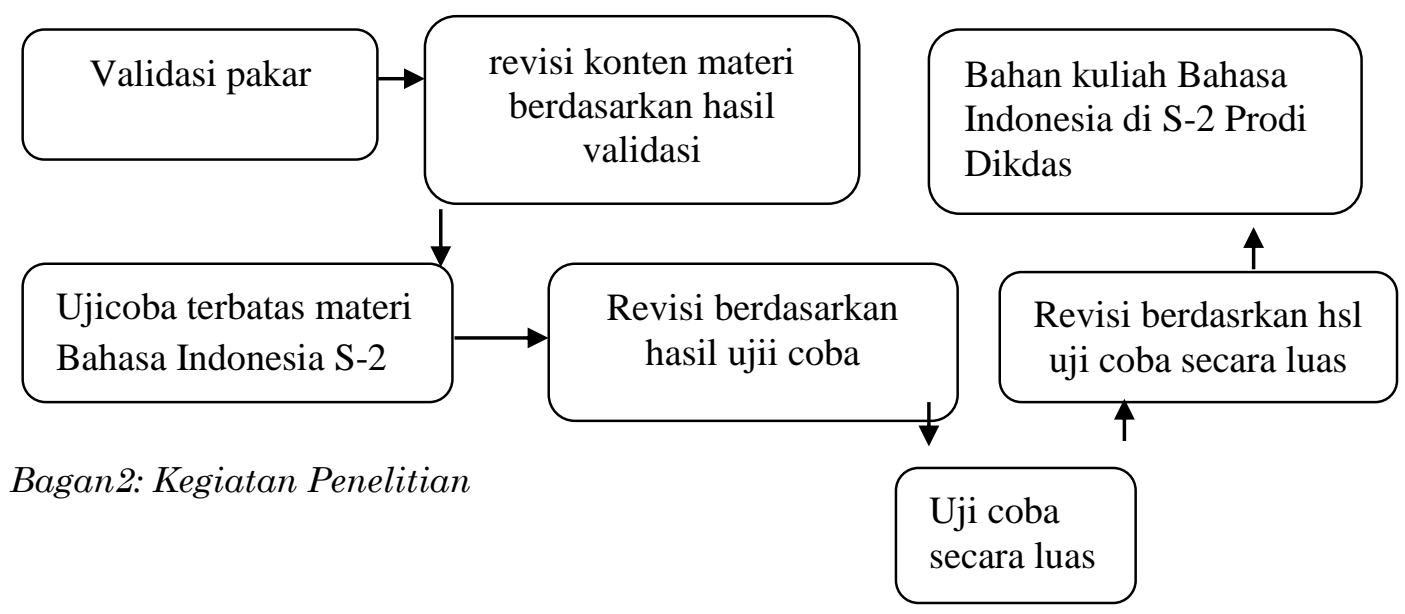

Lokasi penelitian di kampus FKIP Unib yang terletak di Jalan W.R. Supratman Kandang Limum Kota Bengkulu, pada perkuliahan semester ganjil tahun akademik 2020/2021. Obyek penelitiannya adalah pengembangan bahan ajar mata kuliah Bahasa Indonesia. Subyek penelitian adalah mahasiswa S-2 Magister Dikdas.

\section{Instrumen}

Instrumen pengumpulan data berupa kuesner, pedoman wawancara, dan dokumentasi. Wawancara dilakukan untuk mendapat masukan dari mahasiswa terhadap konten bahan ajar Bahasa Indonesia. Dokumentasi dilakukan untuk penambahan data tentang hal-hal yang berhubungan dengan bahan ajar Bahasa Indonesia seperti refrensi-refrensi yang telah ada, yaitu buku Bahasa Indonesia Nasional.

Prosedur kegiatan penelitian dilakukan hanya melalui tahap-tahap berikut; (a) validasi pakar terhadap draf materi yang telah dikembangkan kontennya, (b) revisi konten materi, (c) melakukan ujicoba terbatas, (d) melakukan revisi berdasarkan ujicoba terbatas, dan (g) materi bahan ajar kuliah Bahasa Indonesia berbasis nilai final. 


\section{Teknik Pengumpulan Data}

Teknik pengumpulan data dalam penelitian ini menggunakan, wawancara, kuesner, dan dokumentasi.

\section{Teknik Analisis Data}

Analisis penelitian menggunakan analisis data kualitatif meliputi; reduksi data, display data, verifikasi dan kesimpulan. Analisis dilakukan terhadap data kebutuhan mahasiswa terhadap konten materi bahan ajar Bahasa Indonesia, dan analisis terhadap konten mana saja dan apa saja yang akan dikembangkan.

\section{Hasil}

Dalam penelitian ini telah mengasilkan draf bahan ajar Bahasa Indonesia S-2 Prodi Dikdas Fkip Universitas Bengkulu dengan konten sebagai berikt ini.
A. Literasi, meliputi Hakikat Literasi, Literasi Bahasa Indonesia Hubungan Literasi Dengan
B. Hakikat Bahsasa, meliputi Hakikat bahasa, Bentuk Bahasa, dan Fungsi Bahasa Keterampilan Berbahasa Indonesia Reseptif-Produktif
C. Hakikat Ejaan, meliputi Ejaan bahasa Indonesia, Sejarah Ejaan, dan ejaan Tanda Baca
D. Hakikat Kata, meliputi Jenis Kata Dalam Tata Bahasa Tradisional, Kata Majemuk, Kata Ulang, Kata Berafiks
E. Hakikat Frasa, meliputi Pengertian Frasa, jenis-jenis Frasa.
F. Hakikat Klausa, meliputi Pengertian Klausa, dan Jenis-jenis Klausa
G. Hakikat kalimat, meliputi Pengertian Kalimat, Unsur-unsur Kalimat, Pola
H. Penutup
I. Daftar Pustaka
J. Soal Dan Kunci Jawaban

\section{Pembahasan}

Rancangan awal, materi pengembangan bahan ajar mata kuliah bahasa Indonesia untuk mahasiswa prodi S-2 Dikdas ini meliputi literasi bahasa Indonesia, hakikat, bentuk dan fungsi bahasa, penggunaan kata, bentukan kata, jenis kata, frasa, dan klausa dalam penyusunan kalimat yang baik dan benar, penyusunan kalimat tunggal dan majemuk, penggunaan pedoman umum ejaan bahasa Indonesia (PUEBI) dalam kegiatan menulis, pemahaman dan kemampuan mengembangkan paragraf, wacana, dan sastra bahasa Indonesia, serta teknik penulisan karya ilmiah. Namun, dengan adanya keterbatasan waktu dan dana dalam penyelesaiannya, maka materi bahan bahasa Indonesia S-2 prodi Dikdas yang dikembangkan pada poin hasil di atas.

Rencana materi bahan ajar yang belum terselesaikan dalam penelitian ini, akan dilanjutkan pada penelitian tahun akademi berikutnya.

\section{Kesimpulan}

Berdasarkan hasil penelitian dan pembahasan, maka dapat disimpulkan bahwa penelitian pengembangan bahan ajar bahasa Indonesia S-2 Dikdas ini telah dapat menghasilkan bahan ajar sebagi berikut ini. 
1. Pengembangkan konten Bahasa Indonesia sebagai materi bahan ajar perkuliahan di Prodi S-2 Magister Pendidikan Dasar telah menghasilkan draf bahan ajar.

2. Wujud bahan ajar Bahasa Indonesia sebagai sebuah referensi yang bermakna dan bermanfaat bagi perkuliahan di Prodi S-2 Magister Pendidikan Dasar telah menjadi buku bahan ajar.

\section{Saran}

1. Bagi mahasiswa S-2 Prodi Dikdas telah dapat menggunakan buku

Bahan ajar yang telah ditulis sebagai salah satu sumber yang dapat dipedomani dalam mengerjakan tugas perkulian dan tugas akhir.

2. Kepada peneliti berikutnya, dapat mengembangkan bahan ajar bahasa Indonesia S-2 Prodi dikdas dengan memuat konten pemahaman dan kemampuan mengembangkan paragraf, wacana, dan sastra bahasa Indonesia, serta teknik penulisan karya ilmiah.

\section{Referensi}

Borg, W. R., Gall, M.D., Joyce, P. 2003. Educational Research An Introduction. Seventh Edition.Boston : Pearson Education, Inc.

Creswell, J. W. 1998. Qualitative Inquiry And Research DesignChoosing Among Five Traditions. London : Sage Publications.

Jasmadi, dkk. 2008. Panduan Menyusun Bahan Ajar Berbasis Kompetensi. Jakarta: PT Elex MediaKomputindo

Keraf, Gorys. 1978. Komposisi. Ende : Nusa Indah.

Keraf. 1995. Eksposisi. Jakarta: Penerbit PT Grasindo.

Prastomo. Adi. 2011. Panduan Kreatif Membuat Bahan ajar Inovatif. Jakarta: Diva Press

Suhardi. 2013. Sintaksis: Yogyakarta: UNY Press.

Smitshon, Lisa; Paradis, Johanne; Nicoladis, Ellena. 2014. "Bilingualism and Receptive Vocabulary Achievement: Could Sociocultural Context Make a Difference", Bilingualism: Language and Cognition.

Sparks, Richard L. 2009. "Long-term Relationships amongh Early First Language Skills, Second Language Aptitude, Second Language Affect, and Leter Second Language Proficiency", Applied Psycholinguistics. Cambridge University Press.

Sparks, Richard and Ganschow, Leonore. 2001. "Aptitude for Learning Foreign Language", Annual Review of Applied Linguistics. Cambridge University Press

Siddiq, M. Djauhar dkk. 2008. Pengembangan Bahan Ajar. Direktorat Jenderal Pendidikan Tinggi DEPDIKNAS.

Widodo. Chomsin S. 2008. Panduan Menyusun Bahan Ajar Berbasis Komputer. Jakarta : Media Komputindo 